\title{
SOCIAL DISCOUNT RATE: ASSESSMENT METHODOLOGY
}

\author{
Volodymyr Lipkan ${ }^{1}$ \\ Zaporizhzhia National University, Ukraine \\ Liudmyla Vasiutynska² \\ Odessa National Economic University, Ukraine \\ Ihor Diorditsa ${ }^{3}$ \\ National Aviation University, Ukraine
}

\begin{abstract}
The purpose of the paper is to investigate the assessment methods of social discount rate, to determine its calculation algorithm and to substantiate applied aspects relatively implementation of one or another method during cash flow discounting in social projects. Methodology. The research used such methods as follows: method of comparative analysis was used to find out advantages and limitations of chosen assessment methodologies of the social discount rate; synthesis and generalization methods were used during investigation of the gathered experience concerning application of assessment methodology of social discount rate; logical method was used to substantiate made assumptions; formalization method was used to determine assessment parameters of social discount rate. Results. To achieve the target goal, the following tasks were solved: theoretical studies on the assessment of social discount rate were systemized and the most adapted method for a practical implementation was determined; available pragmatic approaches to the determination of the parameters of social discount rate were investigated and the algorithm of its estimation is substantiated; evaluation of research results were tried out. Practical implications. The article substantiates the necessity of application of social discount rate in the evaluation process of investment projects of the public sector. The theoretical approaches to the choice of the social discount rate were studied. The assessment methods developed and adapted for application in the world practice for discounting public projects were considered. The arguments concerning the expediency of application of the social rate of time preferences for the evaluation of public projects are considered. Different approaches to the determination of the social rate of time preferences are analysed. Value/originality. As a result of the research, parameters of the social rate of time preferences were determined. The application algorithm of the assessment methodology of the social rate of time preferences for public project discounting is indicated. The approbation of the assessment methodology of the social discount rate for discounting projects of the public sector in Ukraine was carried out.
\end{abstract}

Key words: social rate of discount, social rate of time preferences, social opportunity cost of capital, public projects.

JEL Classification: E00, E22, K00, K20

\section{Introduction}

Efficiency estimation of public sector projects in the context of a limited budget fund is the main problem for the government of any country. The reason for the urgency of this problem lies in the social orientation of such projects, and the complexity of solution of social problems creates preconditions for the search for methods that would allow evaluating available alternatives and making sound management decisions regarding the choice of investment priorities for competing projects of the public sector. When it comes to investments, the key moment for efficiency assessment of any project is to determine a discount rate.

Internationally, there are different methodologies relatively parameter determination of the social discount rate, but the social opportunity cost of capital and the social rate of time preferences are the most adapted for the application. However, the current

\footnotetext{
Corresponding author:

${ }^{1}$ Department of Criminal Law and Justice, Zaporizhzhia National University.

E-mail: wlacademic@gmail.com

${ }^{2}$ Department of Finances, Odessa National Economic University.

E-mail: tereza.vaslud@gmail.com

${ }^{3}$ Department of Criminal Law and Procedure, National Aviation University.

E-mail: dior-law@ukr.net
} 
discussions concerning the choice of one or another assessing methodology for the social discount rate cover sufficiently large range of opinions that focus on the problem's determination of the parameters of social discount rate.

Under existing perfect capital markets, rates, which are identified by the mentioned methodologies, will be identical to market interest. However, the reality differs. Firstly, the reason lies in the market distortion, which leads to the fact that the rates do not match both with each other and with the market rate. Thus, there is the issue of choice of an assessment methodology of the social discount rate, which is the most appropriate to the realities. Secondly, if it is referred to assessment methods of the discount rate for public projects then it is necessary to take into account the social nature of these projects. It is necessary to take into consideration the fact that such projects should benefit not a particular person or organization but the society as a whole or certain social group. Market interest rates cannot be applied for cash flow discounting in public projects. The reason is market failures. Therefore, market prices do not reflect marginal benefits and costs for the society. In addition, the government action is especially important for those fields where the market failure exists.

The rapid growth of public expenditures and, in particular, on the social sphere was the reason for the interest of different governments in the development of assessment methodologies of the social rate discount. Consequently, the issue on efficiency improvement of management by limited public financial resources was on the front burner. The application of the discounting methodology for public projects solved a very important issue - the comparison of benefits and costs at different moments of time. If cash flows are not discounted, then the net present value of projects will increase, thus public funds will be used ineffectively.

The public sector, in comparison with the private use of funds, is more regulated. The existence of an approved budget of a government or a territorial community and a set of social tasks that are being solved require considerable resources, but the budget is limited and administrators of budget funds need to make the right choices with regard to available alternatives. And this choice must be justified in terms of the benefits that society receives implementing a particular project. Therefore, developments regarding the choice of the social discount rate are not only theoretical but also applied.

\section{Examination of methods of social discount rate}

The first discussions regarding the need to apply the social rate discount in the projects of the public sector were noted in the XIX century. In the course of time, the issues of choice of assessment methodologies are in the centre of attention of all scholars around the world.
Today, among the basic modern methods, the most applied is the social opportunity cost of capital (SOC) and social rate of time preferences (SRTP).

SOC is acceptable when evaluation of public sector projects is performed using the comparison of the effectiveness of project execution through two alternative ways - a traditional public administrator or a private entrepreneur. The rate, which is determined according to SOC, reflects the alternative costs of the best application of funds ether private or public sector. Both the public and the private sectors compete for the same resources in the investment market. Therefore, in order to justify the decision on a course of investment flows, it is necessary to compare the rate of return on public and private investments. In terms of this approach, the discount rate reflects the lost profits for the public from private sector investments (Marglin, 1963; Kohyama, 2006; Lopez, 2008).

Followers of this method proceeded from the fact that state intervention in the economy would lead to the substitution of private investments by the state ones, if the social task can be solved as a result of the project implementation in the private sector, that is, this refers to the opportunity costs of projects investments carried out due to the state budget. Consequently, the refusal of the alternative on the project implementation in the private sector leads to the loss of the benefits in this regard (Kohyama H., 2006). Based on the fact that, in the private sector, the rate of return on project implementation may cover higher risks than in the public one, to evaluate public sector projects that have private projects as an alternative, it is necessary to use SOC methodology. Thus, the social opportunity cost of capital is defined as the internal profitability of the best private sector project (McKean, 1958) or as the cost of the best alternative for the society (Shukla, 1997).

The social rate of time preferences reflects the willingness of the society to give up consumption at the present time in order to benefit from project implementation in the future. In other words, from the point of view of the social norm of time preferences, this assessment characterizes the compensation that is necessary in connection with the abandonment of the alternative of current consumption in favour of future consumption, that is, where the society has a lost profit too.

It worth paying attention to the fact that social rate of time preferences does not reflect losses or raise of the real value of investments as the social impact is not formed in the realities of added value - it is rather an alternative to the latter. The social effect of the project is understood as the positive changes in living standards of a particular social group or society, which manifests itself in increasing consumption of goods and services, improving the quality of life through qualitatively new progressive alternatives in comparison with existing ones. However, the welfare improvement of individuals due to personal expenses should not be referred to 
the social impact; in other words, it arises only when achievements of the corresponding social indicators do not require cost compensation. Therefore, when it comes to the rate of time preferences it means that a person has to solve the problem of whether to spend now and consume a real product, whether to keep capital or invest it to obtain something ephemeral in the future and, perhaps, not even for personal need but for future generations.

There is the belief that society as a whole has positive time preferences. At the same time, the individual rate differs from the public as the social rate is lower than the individual one (Marglin, 1963). The argument for such a conclusion is based on the statement that the risk of death of an individual is much higher than the risk of death of a society as a whole. In addition, the decision of a certain person at the present moment regarding the issue of saving or consuming will bring benefits in the future not only to a particular person but also to its generation. This is substantiated by the thesis that the social discount rate is lower than the discount rate for commercial projects discounting.

In favour of the use of the SRTP methodology, in comparison with the SOC methodology, it should be included the availability of information support, that is, information that is mediated by macroeconomic indicators is free for any civilized country. Another advantage is that it is possible to evaluate the SRTP rate in the absence of long time series of statistics, which simplifies information collection. In addition, there is a sufficiently large accumulated experience in approbation of the SRTP methodology, which makes it possible to compare and interpret the results.

The SOC methodology is more labour-intensive from the point of view of practical application. This method has more restrictions as a priori provides for the existence of competing projects in the private sector with the same risks as in the public sector.

\section{Parameters assessment of the social discount rate according to the method of Social Rate Time Preferences}

Currently, developed countries have collected a certain practice and formed a sufficiently complete information base to assess parameters of the social rate of time preferences. The successful practice of developed countries regarding the application of this assessment method of the discount rate is quite convincing. However, to obtain adequate results, existing methods use long time series of statistical data (about fifty years, as in the USA and Great Britain, for example). For countries with a transition economy (for example, for Ukraine) the possibility of forming such a powerful information base is limited. The main reason, in particular, is that the state is a sovereign during a short period of time, and its economic system is vulnerable to internal and external shocks. Consequently, the assessment methodology of the social discount rate of public sector projects for countries with a stable economy cannot be fully adapted to implementation in countries with a transition economy. It is this aspect that must be taken into account when choosing assessment methods of the social discount rate.

The basis for calculating the Social Rate of Time Preferences (SRTP) is the maximization task of public utility functions. Furthermore, it is assumed that the significance of the welfare of all individuals is the same for the society, that is, there is no need to introduce weighting coefficient to assess the significance of a particular individual.

Based on the studies of the world scientific community, it is expedient to use the function with constant elasticity of marginal utility in evaluating the social discount rate. The discount rate, according to SRTP, is determined by the Ramsey formula (Ramsey, 1928):

$$
S D R=\delta+L+\mu g
$$

where $g$ is accession rate of consumption per capita; $L$ is a hazard to life; $\delta$ is the net rate of time preferences; $\mu$ is the elasticity of consumption marginal utility.

The parameter $(g)$ determines estimated figures of consumption growth rate per capita. The parameter (L) reflects hazard to life (Newbery, 1992; Pearce, Ulph, 1995). The parameter $(\delta)$ is equal to zero, that is, there is the hypothesis that current generation does not reject its advantages in favour of future generations. Some scholars consider that the parameter $(\mu)$ is unobservable. Nevertheless, this parameter is taken into account in assessment methodologies of social discount rate.

To find the parameter $(\mu)$ of the total utility function, it is necessary to assess the elasticity of consumption marginal utility $(e)$, which is calculated as reciprocal of the parameter $(\mu)$, that is, $e=-\mu$ as due to the utility function, marginal utility is specified by:

$$
\frac{\partial U}{\partial C}=\frac{1}{1-\mu} \cdot(1-\mu) \cdot C^{1-\mu-1}=C^{1-\mu}=C^{-\mu},
$$

subsequently: elasticity $=-\mu \cdot C^{-\mu-1} \cdot \frac{C}{C^{-\mu}}=-\mu$

Turning to the determination of the elasticity parameter of the marginal utility of public consumption, it should be noted that at present there are two ways to assess this parameter. The first is based on the idea that (e) is calculated based on observation over individual savings. In accordance with the second method, the monitoring of income transfer from more affluent members of the society to the less wealthy is carried out. Just as the first one is successfully applied in researches.

An overview of scientific sources made it possible to find out the advantage of the approach regarding the methodology of elasticity determination of the marginal utility of public consumption, which is based on the observation of population savings (Stern, 1977; 
Scott, 1976). For calculations, statistical indicators of population incomes were used:

$$
e=\frac{\mathrm{r}-\delta}{\frac{S}{Y}(r-y)+y},
$$

where $r$ is the opportunity cost of capital; $\delta$ is the net rate of time preferences; $S / Y$ is the average rate of savings; $y$ is expected accession rate of population incomes.

The aforementioned approach was implemented in determining the elasticity of marginal utility for the United Kingdom.

The elasticity of social utility (e) and function parameter of social utility elasticity $\mu$ is assessed as $e=|\mu|$.

\section{Applied aspect of the implementation of SRTP methodology}

Having identified the assessment methodology of the social rate of time preferences, it can be tested. Taking into account the location of the research, macroeconomic indicators of Ukraine were used for the approbation.

The assessment of the parameter $(g)$ was calculated according to an indicator that reflects the actual final consumption of households per capita at comparable prices. Based on the fact that by 2000 the Ukrainian economy was subjected to quite frequent crises, which affected the dynamics of indicators of socio-economic development of the state, the year 2000 was identified as the initial period. The time series is limited by 2013 due to the political events in Ukraine, which began in 2014.

Evaluating the parameter $(L)$, the risk of insufficient future benefits for the society under the project was taken as a basis associated with the probability to die before its implementation. This parameter was calculated as the average value of the number of deceased persons in a particular year to the number of de facto population.

Assessment of the average rate of savings $S / Y$ was determined by analysing the structure of consumer spending, that is, this parameter was defined as the ratio of the funded part of the population income to the total income.

To calculate $(\delta)$, it is accepted the statement that the present generation does not give up its advantages in favour of future generations. This idea is justified taking into account the instability of the economic and political situation in Ukraine, that is, the assessment of the social discount rate for projects implementing in Ukraine is determined for the short or medium term. Therefore, $\delta=0$.

As opportunity cost of capital $(r)$, it is adopted the average weighted rate of interest on deposits of individuals (without demand deposits) in banking institutions. Estimating real interest rate the Fisher equation was used that describes the connection between inflation rate, nominal interest and real interest rate.

The basis for calculating the social rate of time preferences is the Frank Ramsey formula (Ramsey, 1928) which has a mathematical interpretation for the SRTP methodology:

$$
\operatorname{SRTP}=(1+g)^{\mu}(1+\rho)
$$

When calculating the elasticity $(e)$, which is needed to calculate parameter $(\mu)$, the methodology for determining the elasticity of the marginal utility of public consumption by methodology (Stern, 1977; Scott, 1976) is adopted as the basis, formula (4).

The results are presented in Table 1.

\section{Conclusions}

The social discount rate is an instrument that allows conducting an evaluation of public sector projects taking into account changes in cash flows in time. The application of certain tools makes it possible to evaluate more accurately, comparing the benefits and costs in time. Projects that provide a lower return than the social discount rate are not effective for investing.

The systematization of theoretical researches and applied studies on the assessment of the social discount rate has made it possible to conclude that the most used method for practical implementation is the social rate of time preferences. Its advantages can be explained by the substantial experience of approbation of this methodology and the availability of statistical information based on macroeconomic indicators. At the same time, in order to assess the social discount rate adequately, it is necessary to take into account time preferences of the society in terms of consumption, as well as an alternative opportunity for implementation of private sector projects.

The analysis of available approaches to assessment of the social rate of time preferences allowed determining the algorithm of its determination for cash flows

Table 1

Parameters' estimation of the social rate of time preferences for Ukraine

\begin{tabular}{|c|c|c|c|c|c|c|c|c|}
\hline Parameters & $\mathrm{y}$ & $\mathrm{r}$ & $\delta$ & $\mathrm{S} / \mathrm{Y}$ & $\mu$ & $\mathrm{L}$ & $\mathrm{g}$ & SRTP \\
\hline Estimations & 0,1099 & 0,01469 & 0 & 0,0962 & 0,1459 & 0,01586 & 0,1076 & 0,0311 \\
\hline
\end{tabular}

Note: $y$ is expected accession rate of population incomes; $r$ is opportunity cost of capital; $\delta$ is net rate of time preferences; $S / Y$ is average rate of savings; $\mu$ is elasticity of consumption marginal utility; $L$ is hazard to life; $g$ is accession rate of consumption per capita; $S D R$ is social discount rate.

According to the obtained calculations, the social rate of time preferences takes the value of $3.11 \%$. Interpreting its assessment, it can be noted that theoretically, the population can refuse the current benefits in favour of future generations. 
discounting of public projects taking into account the peculiarities of the development of countries with the transition economy.

Considering the peculiarities of economic development and the influence of political factors, as well as the limited information base, time frontiers regarding the application of the social rate of time preferences for the evaluation of public projects in Ukraine have been identified. In particular, estimates for cash flows discounting can be applied in the short and medium term. At the same time, the social discount rate remains adapted only at the appropriate time interval.

The further development of tools for assessment of the social discount rate in accordance with SRTP and SOC methodologies will allow solving the problem of choice of the optimal investment model during the implementation of public-private partnership projects.

\section{References:}

Kohyama, H. (2006) Selecting Discount Rates for Budgetary Purposes. Harvard Law School. Federal Budget Policy Seminar. Briefing Paper, no. 29.

Lopez, H. (2008) The Social Discount Rate: Estimates for nine Latin American Countries. The World Bank. Policy Research Working Paper, no. 4639.

MacKean, R. (1958) Efficiency in Government through Systems Analysis. New York: John Wiley and Sons.

Marglin, S.A. (1963) The social rate of discount on the optimal rate of investment. Quarterly Journal of Economics, vol.77, no. 1, pp. 95-111.

Newbery, D. (1992) The Long Term Discount Rates for the Forest Enterprise. Department of Applied Economics, Cambridge University, mimeo.

Pearce, D.W., Ulph, D. (1995) A Social Discount Rate for the United Kingdom / CSERGE Working Paper 95-01. Centre for Social and Economic Research on the Global Environment. Norwich: University of East Anglia.

Ramsey, F.P. (1928) A Mathematical Theory of Saving. Economic Journal, vol. 38, pp. 543-559.

Scott, M.F. (1976) Investment and growth. Oxford Economic Papers, vol. 28, no. 1, pp. 317-363.

Shukla, D.K. (1997) Estimation of economic discount rate for project appraisal in India. Project Appraisal, vol. 12, no. 1, pp. 53-63.

Stern, N. (1977) The Marginal Valuation of Income / / M. Artis and A. Nobay (eds.). Studies in Modern Economic Analysis. Oxford: Basil Blackwell. 